\title{
Should we Still Publish Case Reports?
}

\section{Petridis $\mathrm{AK}^{\star}$}

Department of Neurosurgery, Sana Kliniken Duisburg, P.O Box: 47055, Duisburg, Germany

There are a number of case reports in my publication history and I had the one or the other conversation with colleagues why to publish case reports. Case reports are not an essential step in someone's career and are more or less a waste of time, is the main argument I was "accused" for. I disagree with this argument and I would like to explain why in this short editorial.

First of all when a first year resident starts her or his career he / she know that there are many steps in a high ladder, which have to be climbed one by one. One such step is publication of research. The case report is short and helps everyone who would like to learn how to publish, to report information concisely and present the data needed, to indicate in the best possible way what the point is.

Apart from the gain a resident has, there is a number of information contained in case reports which help other colleagues to understand the case and read how treatment was managed in order to treat their own patient with the same rare disease. The cases reported are rare in matters of incidence but in absolute numbers and over the whole world the number of "rare" cases can be substantial. With the World Wide Web in hand, the whole world is able to communicate and to share its experiences. After all in every case we treat one single patient with one single entity and it does not really matter to the patient how common or rare his disease is. Sharing experiences with other colleagues and knowing how a case was solved prevents all of us of "reinventing the wheel" again and again.

Publishing rare cases increases the number of such entities and allows further classification and standardization of therapeutic management. Every disease started as a case and in ancient history was reported as a new case.

On the other hand we should be aware that a case report is just one report and not evidence based science. Individual patients can respond to individual therapies in some patients and not at all in others.

In my opinion case reports are still an essential part of clinical science and publishing case reports should be encouraged for young clinicians as well as for senior ones.
*Corresponding author: Dr. Athanasios K. Petridis, Department of Neurosurgery, Sana Kliniken, P.O Box: 47055, Duisburg, Germany, Tel: 492037332425; Fax: 492037330; E-mail: opticdisc@aol.com

Received August 24, 2015; Accepted August 25, 2015; Published August 28, 2015

Citation: Petridis AK (2015) Should we Still Publish Case Reports?. J Neurol Disord 3: e117. doi:10.4172/2329-6895.1000e117

Copyright: ( 2015 Petridis AK. This is an open-access article distributed under the terms of the Creative Commons Attribution License, which permits unrestricted use, distribution, and reproduction in any medium, provided the original author and source are credited. 